\title{
Treatment outcomes of obstructive sleep apnoea in obese community-dwelling children: the NANOS study
}

\author{
María Luz Alonso-Álvarez ${ }^{1,2,3}$, Joaquin Terán-Santos ${ }^{1,2,3}$, \\ Ana Isabel Navazo-Egüia ${ }^{1,3}$, Mónica Gonzalez Martinez ${ }^{1,4}$, \\ María José Jurado-Luque ${ }^{1,2,5}$, Jaime Corral-Peñafiel ${ }^{1,2,6}$, \\ Joaquin Duran-Cantolla1,2,7, José Aurelio Cordero-Guevara ${ }^{1,3}$, \\ Leila Kheirandish-Gozal ${ }^{8}$ and David Gozal ${ }^{8}$, for the Spanish Sleep Network ${ }^{9}$
}

Affiliations: 'Sleep Unit, Hospital Universitario de Burgos, Burgos, Spain. ${ }^{2}$ CIBER of Respiratory Diseases, Instituto Carlos III, CIBERES, Spain. ${ }^{3}$ Hospital Universitario de Burgos (HUBU), Burgos, Spain. ${ }^{4}$ Hospital Universitario Valdecilla, Santander, Spain. ${ }^{5}$ Hospital Val D'Hebron, Barcelona, Spain. ${ }^{6}$ Hospital San Pedro de Alcantara, Caceres, Spain. ${ }^{7}$ Hospital Universitario de Araba, Vitoria, Spain. ${ }^{8}$ Section of Pediatric Sleep Medicine, Department of Pediatrics, Pritzker School of Medicine, Biological Sciences Division, The University of Chicago, Chicago, IL, USA. ${ }^{9}$ For other members of the Spanish Sleep Network, please see the acknowledgements section.

Correspondence: María Luz Alonso Álvarez, MD, Sleep Unit, Hospital Universitario de Burgos, Avda. Islas Baleares SN, 09006, Burgos, Spain. E-mail: mlalonsolahubu.es

ABSTRACT The first line of treatment of obstructive sleep apnoea syndrome (OSAS) in children consists of adenotonsillectomy (T\&A). The aim of the present study was to evaluate treatment outcomes of OSAS among obese children recruited from the community.

A cross-sectional, prospective, multicentre study of Spanish obese children aged 3-14 years, with four groups available for follow-up: group 1: non-OSAS with no treatment; group 2: dietary treatment; group 3: surgical treatment; and group 4: continuous positive airway pressure treatment.

117 obese children ( 60 boys, 57 girls) with a mean age of $11.3 \pm 2.9$ years completed the initial (T0) and follow-up (T1) assessments. Their mean body mass index (BMI) at $\mathrm{T} 1$ was $27.6 \pm 4.7 \mathrm{~kg} \cdot \mathrm{m}^{-2}$, corresponding to a BMI Z-score of $1.34 \pm 0.59$. Mean respiratory disturbance index (RDI) at follow-up was $3.3 \pm 3.9$ events $\cdot \mathrm{h}^{-1}$. Among group 1 children, $21.2 \%$ had an $\mathrm{RDI} \geqslant 3$ events $\cdot \mathrm{h}^{-1}$ at $\mathrm{T} 1$, the latter being present in $50 \%$ of group 2, and $43.5 \%$ in group 3. In the binary logistic regression model, age emerged as a significant risk factor for residual OSAS (odds ratio $1.49,95 \%$ confidence interval $1.01-2.23$; $<<0.05$ ) in obese children surgically treated, and RDI at $\mathrm{T} 0$ as well as an increase in BMI emerged as significant risk factors for persistent OSAS in obese children with dietary treatment (OR 1.82, 95\% CI 1.09-3.02 $(\mathrm{p}<0.03)$ and OR 8.71, 95\% CI 1.24$61.17(\mathrm{p}=0.03))$.

Age, RDI at diagnosis and obesity are risk factors for relatively unfavourable OSAS treatment outcomes at follow-up.

@ERSpublications

Age, RDI and obesity are risk factors for unfavourable OSAS treatment outcomes at follow-up http://ow.ly/MRsnk

Editorial comment in: Eur Respir J 2015; 46: 615-618 [DOI: 10.1183/09031936.00049615]

Received: Jan 252015 | Accepted after revision: March 15 2015 | First published online: June 112015

Clinical trial: This study is registered at clinicaltrials.gov with identifier number NCT01322763.

Support statement: Spanish Respiratory Society (SEPAR) and Mutua Madrileña; L. Kheirandish-Gozal and D. Gozal are supported by a grant HL-65270 form the National Institutes of Health.

Conflict of interest: None declared.

Copyright $\odot$ ERS 2015 


\section{Introduction}

Sleep disordered breathing (SDB) is a highly prevalent condition potentially leading to intermittent hypoxaemia, hypercapnia and disrupted sleep. SDB and, more specifically, obstructive sleep apnoea syndrome (OSAS), have been associated with a large array of neurocognitive, behaviuoral, cardiovascular and metabolic adverse consequences that are particularly prominent in obese children [1-5].

Adenotonsillar hypertrophy emerges as the most important condition associated with OSAS, even among obese children [6-12]. It is widely accepted that the first line of treatment for OSAS consists of surgical removal of upper airway adenoids and tonsils (T\&A). However, persistence of abnormal polysomnographic findings after T\&A is frequent, being reported in $20-60 \%$ of cases, and with obese children constituting a particularly important risk group for residual OSAS [13-22]. However, despite the high rates of obesity in children in both developed and developing countries [23, 24], the overall evidence regarding T\&A outcomes in obese children is scarce.

We conducted the present two-phase study with the aim to assess the contributions of obesity and adenotonsillar hypertrophy to paediatric OSAS. A previous report specifically focussed on the prevalence and risk factors of OSAS in obese children recruited from the community [12]. In the initial study, we found that the prevalence of OSAS in obese children was high, ranging from 21.5 to $39.5 \%$ depending on the cut-off and the polysomnographically obtained respiratory disturbance used [12]. In the present study, we examined the treatment outcomes of OSAS among obese children recruited from the community [12].

\section{Subjects and methods}

A detailed description of the methods pertaining to this cross-sectional, prospective multicentre study has been published previously [12]. Briefly, inclusion criteria were ages between 3 and 14 years, body mass index $(\mathrm{BMI})>95$ th percentile for age and sex, and informed consent from parents or legal caretakers with assent being obtained from children older than 12 years. The study was approved by the local human subject committees of the institutions of the various participating cities in which paediatric sleep laboratories were available. To guarantee the confidentiality of the data, coding of all data was performed, such that personal information was not available to the investigator-based network. Exclusion criteria were failure to fulfil inclusion criteria, and presence of known genetic syndromes or any chronic debilitating disease.

In Spain, the National Health System includes a programme of "well-child visits" from birth to 14 years of age, in which systematic assessments of physical and mental development are conducted at pre-determined ages, and include among many other items, including measurement of height and weight. Based on this initial well-child assessment, obesity in the cohort was defined as the presence of a BMI corresponding to $>95$ th percentile for age and sex using national reference values $[25,26]$.

Decisions on the need for treatment during the first phase of the study were reached by strictly following the Spanish consensus criteria, using a respiratory disturbance index (RDI) $\geqslant 3$ events $\cdot \mathrm{h}^{-1}$ total sleep time (TST) as the cut-off criterion for treatment of OSAS [14]. Based on the severity of OSAS, four groups were accordingly available for follow-up.

Group 1: no polysomnographic evidence of OSAS (i.e. children with RDI $<3$ events $\cdot h^{-1}$ TST). No treatment was administered. A random sample of 52 children who had an RDI $<3$ events. $\mathrm{h}^{-1}$ TST was selected for the present follow-up study.

Group 2: mild OSAS. Children with RDI $\geqslant 3$ events $\cdot h^{-1}$ TST (but $<10$ events $\cdot h^{-1}$ TST) and/or presence of obstructive hypoventilation without significant adenotonsillar hypertrophy (0-2 grade of tonsillar hypertrophy and/or adenoid hypertrophy $<25 \%$ ). The treatment for this group consisted of supervised dietary modification by a nutritionist.

Group 3: moderate-severe OSAS. Children with RDI $\geqslant 3$ events $\cdot \mathrm{h}^{-1}$ TST, and apnoea-hypopnoea index $(\mathrm{AHI}) \geqslant 10$ events $\cdot \mathrm{h}^{-1}$ TST, and/or presence of obstructive hypoventilation with significant adenotonsillar hypertrophy (3-4 grade of tonsillar hypertrophy and/or adenoid hypertrophy $>25 \%$ ) as confirmed by nasopharyngoscopy. The treatment approach was surgical T\&A.

Group 4: moderate-severe OSAS. Children with RDI $\geqslant 3$ events $\cdot h^{-1}$ TST and AHI $\geqslant 10$ events $^{-1} \mathrm{TST}^{-1}$ and/or presence of obstructive hypoventilation without nasopharyngoscopic adenotonsillar hypertrophy. The treatment approach was continuous positive airway pressure (CPAP) treatment via a nasal mask.

65 of the 98 children who were diagnosed with OSAS using the criterion of an RDI $\geqslant 3$ events $h^{-1}$ TST in the first phase of the study completed the specific treatment and follow-up protocol. However, 33 children failed to appear for their scheduled follow-up clinical visits and assessments despite multiple telephone or mailed reminders. No differences in age, sex and BMI z-score were present between the adherent and lost to follow-up groups. 
All participants underwent assessment of their medical and sleep history, filled out a questionnaire about snoring and an abbreviated version of the Pediatric Sleep Questionnaire (PSQ) [27], and were subjected to a comprehensive physical examination that also included craniofacial evaluation by visual inspection, as well as an otolaryngology assessment that included an awake nasopharyngoscopy under topical sedation, followed by an overnight sleep study in the laboratory using standard techniques. Methodological details have been published previously [12].

An overnight polysomnographic study was performed in the laboratory using standard techniques in the presence of one of the caretakers throughout the study. Children arrived accompanied by one of their parents to the sleep laboratory at approximately 19:30-20:00 h, and a lights-off routine was implemented at 21:00 h with discontinuation of the sleep recordings at 08:00 h. After removal of movement and technical artefacts, the studies were scored according to standard criteria as defined by the by the American Academy of Sleep Medicine (AASM) [28]. The proportion of time spent in each sleep stage was expressed as percentage of TST. Apnoea index and AHI were defined as the number of apneas, and the number of apnoeas and hypopneas per hour of TST, respectively. The AHI, obstructive AHI (OAHI), and the respiratory disturbance index (RDI) were also calculated. Furthermore, the flow limitation index was calculated based on all events in which flow limitation was identified [28]. The sleep respiratory disturbance index (SRDI) includes all types of index of respiratory events used in the analysis.

T\&A was performed under general anaesthesia, and if severe OSAS was present, children were admitted to the inpatient paediatric unit for postoperative cardiorespiratory monitoring. Adenoidectomy was performed by curettage and haemostasis by compression or coagulation and tonsillectomy was performed by cold dissection and haemostasis by ligation and bipolar coagulation. In those children who required CPAP treatment, the pressure was adjusted by conventional titration as delineated by the AASM guidelines [29].

\section{Data analysis}

Data are presented as mean \pm sD. Descriptive statistics, Chi-squared analyses for trends, and odd ratios as well as $95 \%$ confidence intervals were calculated. Comparisons of polysomnographic and demographic characteristics before and after treatment were conducted with paired sample t-tests, or analysis of variance followed by post hoc comparisons, with p-values adjusted for unequal variances when appropriate after assessment using the Levene's test for equality of variances, or Chi-squared analyses with the Fisher exact test for dichotomous outcomes. Correlations were performed with the use of linear regression, followed by calculation of Pearson correlation coefficients. To examine potential predictors for unsuccessful treatment (i.e. RDI $>3$ events $\cdot \mathrm{h}^{-1}$ TST after treatment), we performed a general lineal model and logistic regression analysis. A two-tailed $\mathrm{p}<0.05$ was considered as achieving statistical significance. All analyses were conducted with the use of SPSS software (version 22.0; SPPS Inc., Chicago, IL, USA).

\section{Results}

A total of 117 obese children (60 boys, 57 girls) aged $10.3 \pm 2.9$ and $11.3 \pm 2.9$ years at baseline (T0) and follow-up ( $\mathrm{T} 1$ ), completed the initial and follow-up assessments within 11.8 \pm 4.1 months. Their mean BMI at follow-up was $27.6 \pm 4.7 \mathrm{~kg} \cdot \mathrm{m}^{-2}$, corresponding to a BMI z-score of $1.34 \pm 0.59$ (table 1 ).

TABLE 1 Anthropometric characteristics of the study cohort $(n=117)$

\begin{tabular}{lcc} 
& \multicolumn{2}{c}{ Anthropometric measures } \\
\cline { 2 - 3 } & To & T1 \\
\hline Sex & & $60(51.3)$ \\
$\quad$ Male & & $57(48.7)$ \\
$\quad$ Female & $10.35 \pm 2.89$ & $11.32 \pm 2.85$ \\
Age years & $59.90 \pm 21.01$ & $65.25 \pm 21.72$ \\
Weight kg & $1.46 \pm 0.18$ & $1.51 \pm 0.17$ \\
Height $\mathbf{m}$ & $27.06 \pm 4.05$ & $27.63 \pm 4.7$ \\
BMI kg:m ${ }^{-2}$ & $96.84 \pm 0.54$ & $95.26 \pm 6.73$ \\
BMl percentile & $33.82 \pm 3.72$ & $33.82 \pm 3.42$ \\
Neck circumference cm & $0.90 \pm 0.07$ & $0.88 \pm 0.07$ \\
Waist circumference/hip circumference ratio & $103.2 \pm 14.3$ & $105.9 \pm 12.4$ \\
Systolic blood pressure $\mathbf{m m H g}$ & $62.0 \pm 10.7$ & $63.1 \pm 9.4$ \\
Diastolic blood pressure $\mathbf{m m H G}$ & & \\
\hline
\end{tabular}

Data are presented as $\mathrm{n}(\%)$ or mean \pm SD. BMI: body mass index; T0: baseline; T1: follow-up. 


\section{Initial findings: To}

The mean abbreviated PSQ score was 4.56 \pm 3.82 . Based on such a questionnaire, there was a $19.7 \%$ prevalence of OSAS. Nasopharyngoscopic assessments showed that $60.7 \%$ of the children had no evidence of choanal obstruction from enlarged adenoids, and that $31.6 \%$ had grade 0 tonsillar hypertrophy. Craniofacial evaluations revealed that $2.6 \%$ of the children had retrognathia with $18.1 \%$ having dental malocclusion.

For the whole cohort, the mean RDI at T1 was $3.3 \pm 3.9$ events $\cdot h^{-1}$ TST, with a mean obstructive RDI (ORDI) of 3.0 \pm 3.7 events $\cdot \mathrm{h}^{-1}$ TST and a mean obstructive AHI (OAHI) of $1.6 \pm 2.5$ events $\cdot \mathrm{h}^{-1}$ TST. Mean nadir arterial oxygen saturation $\mathrm{SaO}_{2}$ was $90.7 \% \pm 3.5 \%$, and the total time spent with $\mathrm{SaO}_{2}<90 \%$ (T90\%) was $0.2 \% \pm 0.9 \%$ of TST; 52 children had no evidence of OSA (group 1), with 36 children being allocated to group 2, 23 children in group 3 (T\&A) and six children in group 4 (CPAP treatment) (table 2).

\section{Follow-up findings: $\mathrm{T1}$}

Using an SRDI $\geqslant 3$ events. $\mathrm{h}^{-1}$ TST, the prevalence of OSAS was $17.1-34.2 \%$ depending on OAHI, ORDI or RDI as the selected respiratory disturbance index. Based on a classification of OSAS as mild (SRDI $\geqslant 3$ and $<5$ events $\cdot \mathrm{h}^{-1}$ TST), moderate (SRDI $\geqslant 5$ and $<10$ events $\cdot \mathrm{h}^{-1}$ TST) or severe (SRDI $>10$ events $\cdot \mathrm{h}^{-1}$ TST), severe OSAS was present in $3.4-8.5 \%$ of the children (table 3 ).

Using an RDI $\geqslant 3$ events. $h^{-1}$ TST on polysomnography (PSG) at follow-up for the presence of OSAS: Among subjects included in group 1 (non-OSAS, RDI $<3$ events $\mathrm{h}^{-1}$ TST at T0), $41(78.8 \%)$ of children remained with an RDI $<3$ events. ${ }^{-1}$ TST at T1 (non-OSAS) at follow-up, while $11(21.2 \%)$ had an RDI $\geqslant 3$ events. $\mathrm{h}^{-1}$ TST at T1 (incident cases). Among group 2 (mild OSAS who received dietary treatment at

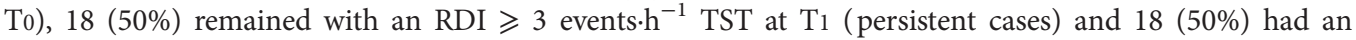
$\mathrm{RDI}<3 / \mathrm{h}$ TST at $\mathrm{T} 1$ (remission cases). In Group 3 (moderate-severe OSAS who received surgical treatment) 10 (43.5\%) remained with an RDI $\geqslant 3$ events $\cdot h^{-1} \mathrm{TST}$ at $\mathrm{T} 1$ (residual cases), while 13 (56.5\%) had $\mathrm{RDI}<3$ events.h ${ }^{-1}$ TST at $\mathrm{T} 1$ (resolved cases). In group 4 (moderate-severe OSA who received CPAP treatment) one (16.6\%) remained with an RDI $\geqslant 3$ events $\cdot h^{-1}$ TST at T1 (residual cases), while five (83.3\%) had RDI $<3$ events. $h^{-1}$ TST at T1 (controlled cases).

The residual OSAS were $30.4,13.1$ and $7.2 \%$ for $\mathrm{OAHI} \geqslant 1, \mathrm{OAH} 1 \geqslant 3$ and $\mathrm{OAHI} \geqslant 5$, respectively. Table 4 shows incidence, persistence and residual OSAS based on the different cut-off criteria used (RDI $\geqslant 3$, $\mathrm{OAHI} \geqslant 3$, OAHI $\geqslant 1$ ) on PSG for diagnosis of OSAS.

General linear model approaches were used to assess differences between study groups. Statistically significant differences in the distribution of RDI and AHI between groups were observed $(\mathrm{p}<0.001)$, but not in BMI and age $(\mathrm{p}=0.104$ and $\mathrm{p}>0.05$, respectively). After adjusting for age and BMI, age was significantly associated with T0-T1 RDI changes $(\mathrm{p}<0.05)$ and AHI changes $(\mathrm{p}<0.05)$.

To examine potential predictors in development or persistence of OSAS at $\mathrm{T} 1$, a general linear model approach was used. Comparing the incident group $(n=11)$ and the non-OSA group that were originally included in group 1 , there were no significant differences in age and BMI, but significant differences in the degree of tonsillar hypertrophy emerged, with proportion of children with grade 3-4 tonsillar hypertrophy in the incident cases being higher $(27.3 \%)$ than among those who remained free of OSAS (2.4\%, $\mathrm{p}<0.05$; table 5$)$. Comparisons of group 2 subjects with persistent OSAS $(n=18)$ to those without evidence of OSAS at $\mathrm{T}_{1}$ (remission cases), the $\mathrm{BMI}$ in the remission cases decreased, while BMI increased in the group with persistent OSAS (change in BMI from To to T1: $-0.33 \pm 2.83$ and $0.36 \pm 2.05 \mathrm{~kg} \cdot \mathrm{m}^{-2}$, respectively). The degree of tonsillar hypertrophy was not statistically significant between those with remission compared to those with persistent OSAS ( $p>0.05$; table 5). In group 3, the residual group $(\mathrm{n}=10)$ and the resolved cases $(\mathrm{n}=13)$, revealed no significant differences in either age or BMI. However, the risk of residual OSAS increased with increasing age and BMI (table 5).

A statistically significant association between BMI change from To to $\mathrm{T}_{1}$ (BMI1-BMI0) and parallel RDI changes emerged $(r=0.269 ; p=0.003)$ for the whole cohort, and was present in group $2(r=0.362, p=0.03)$ and group $3(\mathrm{r}=0.661 ; \mathrm{p}<0.001)$.

In the binary logistic regression model, in group 1 (non-OSAS) and group 2 (mild OSAS with dietary treatment), using OSAS a dichotomous outcome variables, sex, age, RDI at T0, BMI1-BMI0, retrognathia, tonsillar hypertrophy and adenoid hypertrophy $(>25 \%)$ as a co-variables, the odds ratio for tonsillar hypertrophy was $4.37(\mathrm{p}=0.291)$ in group 1 . In group 2, RDI at To and BMI-BMI0 emerged as a significant risk factors for OSAS persistent (OR 1.82, 95\% CI 1.09-3.02 $(\mathrm{p}<0.03)$ and OR 8.71, 95\% CI $1.24-61.17(\mathrm{p}=0.03))$ respectively.

In the binary logistic regression model using OSAS as a dichotomous outcome variable, and sex, age, RDI at T0, BMI-BMI0 and retrognathia as co-variables, we found that age emerged as a significant risk factor for residual OSAS (OR 1.49, 95\% CI 1.01-2.23, p=0.047) in group 3, surgically treated. Although not statistically significant, the OR for BMI change was $2.93(\mathrm{p}=0.523)$ and $8.57(\mathrm{p}=0.268)$ for retrognathia. 
TABLE 2 Polysomnographic measures at baseline (T0) and follow-up (T1) in 117 obese children in the four groups studied

Group 1 (non-0SA)

Group 2 (mild OSA, dietary treatment)
Group 3 Imoderatesevere OSA treated surgically)

\section{Participants $\mathbf{n}$}

Respiratory measures

Respiratory events $n$

T0

T1

Central apnoeas $\mathrm{n}$

To

T1

Obstructive apnoeas $\mathrm{n}$

To

T1

Mixed apnoeas $\mathrm{n}$

To

$\mathrm{T} 1$

Hypopnoeas $n$

To

$\mathrm{T} 1$

Flow-limited events $n$

To

$\mathrm{T} 1$

RDI events $\cdot h^{-1}$ TST

To

T1

REMS RDI events $\cdot \mathrm{h}^{-1}$ TST

To

T1

NREMS RDI events $\cdot \mathrm{h}^{-1}$ TST

To

T1

ORDI events $\cdot \mathrm{h}^{-1}$ TST

To

T1

Central AHI events $\cdot h^{-1}$ TST

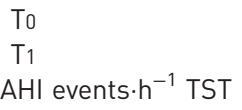

OAHI events $\cdot h^{-1}$ TST

$\mathrm{T} 0$
$\mathrm{~T} 1$

Apnoea index events $\cdot \mathrm{h}^{-1}$ TST

To

$\mathrm{T} 1$

Hypopnoea index events $\cdot \mathrm{h}^{-1}$ TST

To

T1

Flow limited index events. $\mathrm{h}^{-1}$ TST

To

T1

Baseline $\mathrm{SaO}_{2}$

To

T1

Mean $\mathrm{SaO}_{2}$

To

T1

Nadir $\mathrm{SaO}_{2}$

To

$\mathrm{T} 1$

T90\%

To

$\mathrm{T} 1$
52

$9.56 \pm 5.32$

$14.60 \pm 18.69^{\text {वी }}$

$0.62 \pm 1.10$

$0.94 \pm 3.84$

$0.65 \pm 1.62$

$2.04 \pm 5.45$

$0.02 \pm 0.14$

$0.62 \pm 3.64$

$2.96 \pm 3.51$

$5.00 \pm 8.61$

$5.60 \pm 4.70$

$6.17 \pm 11.28$

$1.48 \pm 0.83$

$2.24 \pm 2.93$

$1.74 \pm 2.12$

$1.57 \pm 2.80$

$1.17 \pm 1.09$

$2.02 \pm 3.14$

$1.34 \pm 0.85$

$2.06 \pm 2.83$

$0.09 \pm 0.18$

$0.15 \pm 0.64$

$0.57 \pm 0.60$

$1.16 \pm 1.82^{7}$

$0.20 \pm 0.32$

$0.55 \pm 1.32$

$0.47 \pm 0.57$

$0.76 \pm 1.37$

$0.86 \pm 0.72$

$0.93 \pm 1.68$

$98.27 \pm 1.43$

$97.96 \pm 1.01$

$96.50 \pm 1.49$

$96.31 \pm 1.18$

$91.29 \pm 3.63$

$91.06 \pm 3.10$

$1.31 \pm 5.13$

$0.23 \pm 1.28$
36

$51.44 \pm 32.37$

$28.14 \pm 27.89^{\#}$

$3.29 \pm 10.04$

$2.11 \pm 6.03$

$4.89 \pm 9.37$

$3.47 \pm 5.85$

$0.42 \pm 1.10$

$0.64 \pm 1.58$

$16.39 \pm 19.32$

$9.44 \pm 14.07^{1}$

$26.53 \pm 19.56$

$12.75 \pm 16.50^{9}$

$8.57 \pm 8.35$

$4.70 \pm 4.91^{\#}$

$6.07 \pm 6.11$

$3.69 \pm 4.31^{\text {ๆ }}$

$6.03 \pm 5.68$

$4.14 \pm 5.10^{\text {I }}$

$7.98 \pm 4.91$

$4.34 \pm 4.48^{\#}$

$0.59 \pm 2.03$

$0.35 \pm 0.90$

$3.57 \pm 3.90$

$2.25 \pm 2.99$ शी

$1.40 \pm 2.82$

$1.02 \pm 1.64$

$2.70 \pm 3.01$

$1.58 \pm 2.60$

$4.36 \pm 3.26$

$2.07 \pm 2.81^{\pi}$

$97.60 \pm 1.83$

$97.54 \pm 1.36$

$96.08 \pm 1.64$

$96.17 \pm 1.36$

$90.44 \pm 3.02$

$90.31 \pm 3.95$

$3.27 \pm 14.70$

$0.28 \pm 0.68$
23

$131.13 \pm 130.60$

$24.39 \pm 24.71^{\#}$

$6.0 \pm 10.72$

$0.91 \pm 1.70^{\circ}$

$37.13 \pm 64.40$

$1.00 \pm 2.31^{\pi}$

$3.17 \pm 10.08$

$0.09 \pm 0.42$

$53.74 \pm 70.76$

$8.70 \pm 16.39$ ?

$30.17 \pm 37.99$

$13.00 \pm 15.68^{\text {शी }}$

$18.92 \pm 20.15$

$3.60 \pm 3.50^{\#}$

$21.14 \pm 30.85$

$6.42 \pm 12.29$ ?

$16.15 \pm 20.30$

$3.10 \pm 3.54^{91}$

$17.88 \pm 19.06$

$3.33 \pm 3.60^{\#}$

$0.85 \pm 1.55$

$0.12 \pm 0.22^{\text {? }}$

$13.54 \pm 19.77$

$1.38 \pm 2.38^{\#}$

$6.74 \pm 12.64$

$0.28 \pm 0.43^{9}$

$7.62 \pm 10.16$

$1.22 \pm 2.25^{\pi}$

$4.08 \pm 4.85$

$1.89 \pm 2.11^{11}$

$98.48 \pm 1.24$

$98.35 \pm 0.94$

$95.91 \pm 2.64$

$96.57 \pm 1.30$

$86.86 \pm 10.96$

$90.27 \pm 3.73^{\text {T }}$

$2.54 \pm 10.25$

$0.09 \pm 0.34$
Group 4 Imoderate-

severe OSA treated with CPAPI
$173.0 \pm 115.15$

$16.50 \pm 34.07^{9}$

$1.17 \pm 1.47$

$4.17 \pm 5.49$

$35.33 \pm 76.35$

$1.17 \pm 2.40$

$0.83 \pm 1.33$

$0.0 \pm 0.0$

$120.67 \pm 107.22$

$10.83 \pm 25.56$

$14.83 \pm 15.54$ $0.50 \pm 0.84^{\text {7 }}$

$30.10 \pm 18.33$ $2.80 \pm 5.83^{9}$

$36.99 \pm 33.66$ $1.92 \pm 1.27^{11}$

$27.67 \pm 17.40$

$1.53 \pm 3.26^{9}$

$29.29 \pm 18.28$

$2.10 \pm 4.92^{\pi}$

$0.19 \pm 0.17$

$0.69 \pm 0.94$

$27.36 \pm 18.89$

$2.05 \pm 4.77^{1,+}$

$6.34 \pm 13.25$

$0.88 \pm 1.34$

$21.19 \pm 18.54$

$1.86 \pm 4.36^{\text {1,+ }}+$

$2.62 \pm 2.29$

$0.07 \pm 0.14^{91,+}$

$99.17 \pm 1.16$

$99.17 \pm 0.41$

$96.17 \pm 1.16$

$97.00 \pm 1.09$

$87.50 \pm 3.61$ $93.00 \pm 1.55^{11,+}$

$0.28 \pm 0.36$ $0.00 \pm 0.00$ 
TABLE 2 Continued

Group 1 (non-0SA)

Group 2 (mild OSA, dietary treatment)
Group 3 Imoderatesevere OSA treated surgically)
Group 4 Imoderatesevere OSA treated with CPAPJ

\begin{tabular}{|c|c|c|c|c|}
\hline \multicolumn{5}{|l|}{ ODI } \\
\hline To & $0.18 \pm 0.50$ & $1.95 \pm 4.00$ & $6.84 \pm 21.60$ & $19.88 \pm 19.25$ \\
\hline $\mathrm{T}_{1}$ & $0.24 \pm 0.56$ & $1.57 \pm 2.67$ & $0.94 \pm 2.38$ & $0.42 \pm 0.57^{\pi++}$ \\
\hline \multicolumn{5}{|c|}{ Peak $P_{\mathrm{ETCO}_{2}} \mathrm{mmHg}$} \\
\hline $\mathrm{T}_{1}$ & $47.15 \pm 5.11$ & $44.26 \pm 5.45$ & $47.84 \pm 5.38$ & $50.00 \pm 3.69$ \\
\hline \multicolumn{5}{|c|}{$\mathrm{PETCO}_{2}>50 \mathrm{mmHg} \% \mathrm{TST}$} \\
\hline To & $2.79 \pm 6.62$ & $4.30 \pm 11.34$ & $10.01 \pm 22.11$ & $1.82 \pm 4.45$ \\
\hline To & $77.44 \pm 10.09$ & $80.89 \pm 16.06$ & $85.76 \pm 11.92$ & $83.50 \pm 8.26$ \\
\hline $\mathrm{T}_{1}$ & $75.10 \pm 10.45^{\natural}$ & $77.03 \pm 17.58^{q}$ & $76.05 \pm 12.37^{\#}$ & $76.67 \pm 8.82^{\eta,+}$ \\
\hline \multicolumn{5}{|c|}{ Sleep measures } \\
\hline \multicolumn{5}{|c|}{ Sleep efficiency \% } \\
\hline To & $79.99 \pm 10.02$ & $78.89 \pm 10.61$ & $84.75 \pm 8.27$ & $69.76 \pm 21.61$ \\
\hline $\mathrm{T}_{1}$ & $81.54 \pm 9.89$ & $79.74 \pm 16.55$ & $83.11 \pm 11.36$ & $81.86 \pm 13.69$ \\
\hline To & $123.72 \pm 54.33$ & $123.31 \pm 79.70$ & $127.98 \pm 75.81$ & $222.30 \pm 74.64$ \\
\hline $\mathrm{T}_{1}$ & $137.30 \pm 68.28$ & $150.39 \pm 80.90$ & $126.13 \pm 48.35$ & $158.00 \pm 60.68$ \\
\hline \multicolumn{5}{|c|}{ Awake \%TST } \\
\hline To & $22.63 \pm 13.68$ & $22.76 \pm 18.82$ & $15.52 \pm 11.16$ & $23.00 \pm 23.56$ \\
\hline $\mathrm{T} 1$ & $24.48 \pm 16.38$ & $19.60 \pm 20.56$ & $18.10 \pm 15.17$ & $14.70 \pm 10.06$ \\
\hline \multicolumn{5}{|c|}{ N1 \% } \\
\hline To & $11.82 \pm 8.00$ & $11.29 \pm 10.70$ & $12.02 \pm 7.80$ & $14.25 \pm 5.90$ \\
\hline $\mathrm{T}_{1}$ & $12.58 \pm 8.13$ & $9.82 \pm 8.97$ & $11.29 \pm 6.85$ & $9.19 \pm 5.80$ \\
\hline \multicolumn{5}{|c|}{$\mathrm{N} 2 \%$} \\
\hline To & $43.04 \pm 8.16$ & $43.03 \pm 9.93$ & $42.50 \pm 12.30$ & $40.41 \pm 11.04$ \\
\hline $\mathrm{T}_{1}$ & $42.67 \pm 8.75$ & $41.79 \pm 12.77$ & $43.32 \pm 11.61$ & $46.31 \pm 8.23$ \\
\hline \multicolumn{5}{|c|}{ N3 \% } \\
\hline To & $25.95 \pm 10.85$ & $29.21 \pm 12.17$ & $27.70 \pm 23.85$ & $36.02 \pm 16.13$ \\
\hline To & $0.22 \pm 0.87$ & $1.45 \pm 3.22$ & $1.00 \pm 3.33$ & $7.10 \pm 8.07$ \\
\hline $\mathrm{T}_{1}$ & $0.15 \pm 0.64$ & $1.31 \pm 3.82$ & $1.24 \pm 4.46$ & $1.00 \pm 1.41$ \\
\hline \multicolumn{5}{|c|}{ 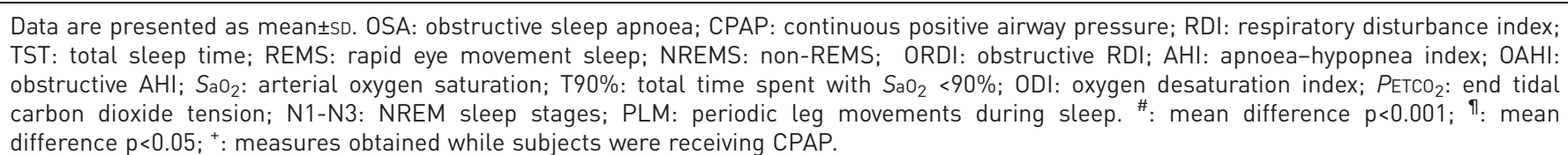 } \\
\hline
\end{tabular}

When we used a general lineal model for repeated measures, only in group 3 did surgically treated age $>11$ years $(\mathrm{p}=0.033)$, retrognathia $(\mathrm{p}=0.026)$ and neck circumference $(\mathrm{p}=0.002)$ emerged as significant risk factors for residual OSAS.

\section{Discussion}

This study prospectively assessed the outcomes of OSAS in a community-based cohort of children in whom obesity was diagnosed by their primary care physicians. We previously described the high prevalence of both snoring and OSAS in obese "healthy" children [12]. Here we found that, in obese 
TABLE 3 Prevalence and severity of OSAS based on different cut-off criteria in 117 obese children at baseline (To) and follow-up (T1)

Diagnostic criterion
Prevalence $(95 \% \mathrm{Cl})$

$\begin{array}{lll}\text { Prevalence }(95 \% \mathrm{Cl}) & \begin{array}{l}\text { Mild OSAS }(\geqslant 3 \text { and } \\ \left.<5 \text { events } \cdot \mathrm{h}^{-1} \text { TST }\right)\end{array}\end{array}$

Participants $\mathrm{n}$

OSAS (ORDI $\geqslant 3$ events $\cdot h^{-1}$ TST)

OSAS (OAHI $\geqslant 3$ events $\cdot h^{-1}$ TST)

OSAS (OAHI $>1$ event $\cdot h^{-1}$ TST)
248

$39.5 \%(33.4-45.6 \%)$

$35.9 \%(29.9-41.9 \%)$

$21.5 \%(16.3-26.6 \%)$

$46.6 \%(40.6-53 \%)$
117

$<5$ events $\cdot h^{-1}$ TST)

$40(34.2 \%)(25.2 \%-43.2 \%)$

$38(32.5 \%)(23.6 \%-41.4 \%)$

$20(17.1 \%)(9.8 \%-24.3 \%)$

$44(37.6 \%)(28.4 \%-46.8 \%)$

To T1

117

117

$17(14.5) \quad 15(12.8)$

$14(12)-11(9.4)$

$12(10.3) \quad 16(13.7)$
OSAS (RDI $\geqslant 3$ events $\cdot h^{-1}$ TST)

Severity-based prevalence

\section{Moderate OSAS I $\geqslant 5$ and}

$<10$ events $\cdot h^{-1}$ TST)

To T1

Severe OSAS

117

$22(18.8)$

18 (15.4)

117

14 (12)

$10(8.5) \quad 5(4.3)$

$31(26.5)$

$30(25.6)$

Data are presented as $\mathrm{n}(\%)(95 \% \mathrm{CI})$ or $\mathrm{n}(\%)$, unless otherwise stated. OSAS: obstructive sleep apnoea syndrome; TST: total sleep time; RDI: respiratory disturbance index; ORDI: obstructive respiratory disturbance index; OAHI: obstructive apnoea-hypopnoea index.

TABLE 4 Incidence, persistence and residual OSAS based on different cut-off criteria in 117 obese children

Groups for follow-up (To-T1) $n=117$

\begin{tabular}{|c|c|c|c|c|c|c|c|c|}
\hline \multirow{2}{*}{$\begin{array}{l}\text { Groups at } T_{1} \\
\text { Diagnostic criteria }\end{array}$} & \multicolumn{2}{|c|}{ Non-OSAS } & \multicolumn{2}{|c|}{$\begin{array}{l}\text { Mild OSAS treated } \\
\text { by diet }\end{array}$} & \multicolumn{2}{|c|}{$\begin{array}{c}\text { Moderate-severe } \\
\text { OSAS treated surgically }\end{array}$} & \multicolumn{2}{|c|}{$\begin{array}{c}\text { Moderate-severe } \\
\text { OSAS treated with CPAP }\end{array}$} \\
\hline & Non-OSAS & Incident cases & Remission cases & Persistent cases & Resolved cases & Residual cases & Resolved cases & Residual cases \\
\hline $\mathrm{RDI} \geqslant 3$ & $41(78.84)$ & $11(21.15)$ & $18(50)$ & $18(50)$ & 13 (56.5) & $10(43.5)$ & $5(83.3)$ & $1(16.6)$ \\
\hline $\mathrm{OAHI} \geqslant 3$ & $45(86.5)$ & 7 (13.5) & $27(75)$ & $9(25)$ & $20(86.9)$ & $3(13.1)$ & 5 (83.3) & $1(16.6)$ \\
\hline $\mathrm{OAHI} \geqslant 1$ & 33 (70.2) & 14 (29.8) & 19 (46.3) & $22(53.6)$ & $16(69.6)$ & $7(30.4)$ & $5(83.3)$ & $1(16.6)$ \\
\hline \multicolumn{9}{|c|}{$\begin{array}{l}\text { Data are presented as } \mathrm{n}(\%) \text {. OSAS: obstructive sleep apnoea syndrome; CPAP: continuous positive airway pressure; RDI: respiratory disturbance index; OAHI: obstructive apnoea- } \\
\text { hypopnoea index. For RDI } \geqslant 3 \text { and OAHI } \geqslant 3 \text {, number of subjects per group were non-OSAS: } 52(44.4 \%) \text {; mild OSAS treated by diet: } 36 \text { (30.8\%); moderate-severe OSAS treated surgically: } 23 \\
(19.7 \%) \text {; and moderate-severe OSAS treated with CPAP: } 6(5.1 \%) \text {. For OAHI } \geqslant 1 \text {, number of subjects per group were non-OSAS: } 47 \text { (40.2\%); mild OSAS treated by diet: } 41 \text { (35\%); moderate- } \\
\text { severe OSAS treated surgically: } 23(19.7 \%) \text {; and moderate-severe OSAS treated with CPAP: } 6(5.1 \%) \text {. }\end{array}$} \\
\hline
\end{tabular}


TABLE 5 Characteristics of the variables included in the general linear model

\begin{tabular}{|c|c|c|c|c|c|c|c|c|c|}
\hline & \multicolumn{2}{|c|}{ RDI } & \multicolumn{2}{|c|}{ AHI } & \multicolumn{2}{|c|}{ BMI } & \multirow[t]{2}{*}{ BMl1-BMlo } & \multirow[t]{2}{*}{ Age at $\mathrm{T}_{1}$ years } & \multirow[t]{2}{*}{ TH \% } \\
\hline & To & $\mathrm{T}_{1}$ & To & $\mathrm{T}_{1}$ & To & $\mathrm{T}_{1}$ & & & \\
\hline \multicolumn{10}{|l|}{ Non-OSAS } \\
\hline Non-OSAS $n=41$ & $1.40 \pm 0.79$ & $0.92 \pm 0.75$ & $0.52 \pm 0.52$ & $0.39 \pm 0.42$ & $25.79 \pm 3.24$ & $26.16 \pm 3.99$ & $0.37 \pm 2.38$ & $10.93 \pm 2.73$ & 2.4 \\
\hline Incident cases $n=11$ & $1.80 \pm 0.91$ & $7.15 \pm 2.79$ & $0.79 \pm 0.83$ & $4.06 \pm 2.12$ & $27.96 \pm 4.02$ & $28.35 \pm 5.37$ & $0.39 \pm 2.04$ & $11.59 \pm 2.64$ & 27.3 \\
\hline \multicolumn{10}{|l|}{ Mild OSAS } \\
\hline Remission cases $n=18$ & $5.97 \pm 2.19$ & $1.71 \pm 0.89$ & $2.62 \pm 1.63$ & $0.60 \pm 0.64$ & $27.84 \pm 4.04$ & $27.50 \pm 5.02$ & $-0.33 \pm 2.82$ & $12.18 \pm 2.36$ & 0 \\
\hline Persistent cases $n=18$ & $11.18 \pm 6.29$ & $7.69 \pm 5.47$ & $4.53 \pm 5.17$ & $3.91 \pm 3.50$ & $27.94 \pm 3.02$ & $28.30 \pm 4.00$ & $0.36 \pm 2.05$ & $12.20 \pm 2.24$ & 11.1 \\
\hline \multicolumn{10}{|c|}{ Moderate-severe OSAS treated surgically } \\
\hline Resolved cases $n=13$ & $20.57 \pm 24.21$ & $1.22 \pm 0.87$ & $13.99 \pm 23.98$ & $0.43 \pm 0.55$ & $26.22 \pm 5.19$ & $26.42 \pm 3.07$ & $0.19 \pm 3.81$ & $9.69 \pm 3.62$ & 0 \\
\hline Residual cases $n=10$ & $16.76 \pm 14.23$ & $6.70 \pm 3.18$ & $12.95 \pm 13.70$ & $2.63 \pm 3.24$ & $25.92 \pm 3.87$ & $27.75 \pm 4.96$ & $1.83 \pm 1.45$ & $10.91 \pm 3.67$ & 0 \\
\hline \multicolumn{10}{|c|}{ Moderate-severe OSAS treated with CPAP } \\
\hline Resolved cases $n=5$ & $28.12 \pm 19.77$ & $0.42 \pm 0.18$ & $24.87 \pm 19.99$ & $0.10 \pm 0.17$ & $33.31 \pm 3.55$ & $35.21 \pm 3.90$ & $1.90 \pm 1.74$ & $11.82 \pm 2.25$ & 0 \\
\hline Residual cases $n=1$ & 40.00 & 14.70 & 39.83 & 11.79 & 40.12 & 39.37 & -0.75 & 16.75 & 0 \\
\hline
\end{tabular}


children with OSAS treated by adenotonsillectomy, there was a high percentage of residual OSAS, and that in a group of obese children with OSAS without adenotonsillar hypertrophy treated with nutritional interventions, there was a high percentage of persistent OSAS. Furthermore, obese children without OSAS during the initial assessment showed a high risk of developing OSAS at follow-up. Finally, we also identified a portion of obese children with OSAS who presented no evidence of adenotonsillar hypertrophy and were therefore best managed with CPAP.

Some methodological issues deserve comment. First, the prospectively designed recruitment of this cohort was based on the initial diagnosis of obesity during routine well-child visits, thereby preventing any potential a priori selection bias. Therefore, none of these children had been previously evaluated for snoring or were clinically suspected or treated for OSAS. As in the previous study [12], we used previously established consensus guidelines in Spain using a RDI $\geqslant 3$ events. $\mathrm{h}^{-1}$ TST as the cut-off criterion for treatment of OSAS [14], and such an approach resulted in an OSAS prevalence of $34.2 \%$. However, even if we apply alternative criteria (e.g. ORDI $\geqslant 3$ events. $\mathrm{h}^{-1}$ TST, OAHI $\geqslant 3$ events. $\mathrm{h}^{-1}$ TST, or AHI $>1$ events.h ${ }^{-1}$ TST), the prevalence would still be very high (i.e. $17.1 \%$ to $37.6 \%$ for AHI $>1$ event.h ${ }^{-1}$ TST) $[13,14]$. As shown in table 3, we also examined the distribution of OSAS and the effects of treatment according to other widely accepted severity cut-off values.

The treatment of choice for OSAS in children is adenotonsillectomy; however, many studies show that in obese children the success rate of surgery (expressed as a post-operative OAHI $<1$ event.h ${ }^{-1}$ TST or $<5$ events.h ${ }^{-1}$ TST) is lower [30-36]. In a meta-analysis, $49 \%$ of obese children had a postoperative $\mathrm{AHI}<5$ events $\cdot \mathrm{h}^{-1}$ TST, $25 \%$ of children had an AHI $<2$ events $\cdot \mathrm{h}^{-1}$ TST and only $12 \%$ of children had a postoperative AHI $<1$ event $\cdot h^{-1}$ TST [21]. In a retrospective multicentre study of 578 children that included approximately 50\% obese children, T\&A resulted in a significant reduction of AHI, but complete resolution of OSA was recorded in only $27.2 \%$, using a post-T\&A AHI cut-off of $<1$ event.h ${ }^{-1}$ TST [33]. In this particular study, age $(<$ or $\geqslant 7$ years) and BMI Z-score emerged as the two principal factors contributing to post-T\&A AHI outcomes [33]. An earlier prospective study carried out in 110 children revealed that only $25 \%$ had normalisation of their postoperative PSG, and that pre-T\&A AHI and obesity were the major outcome determinants [30]. In another series, obese children had an OR of 3.7 (95\% CI 1.3-10.8) for residual OSAS [35]. In the only randomised controlled trial to date, normalisation of polysomnographic findings was observed in a large proportion of children in the early adenotonsillectomy group when compared with the watchful waiting group (79 versus $46 \%$ ), but occurred less frequently in obese children [34]. Similarly unfavourable treatment outcomes of adenotonsillectomy (postoperative OAHI $<1$ event $\cdot h^{-1}$ TST in $22.7-25 \%$ of cases) have been reported previously in a study of both lean and obese children with OSAS [37].

In our study, $43.5 \%$ of children treated by T\&A had residual OSAS defined as a postsurgical RDI $\geqslant 3$ events $\cdot \mathrm{h}^{-1}$ TST, even if we apply alternative criteria (e.g. AHI $\geqslant 3$ events $\cdot \mathrm{h}^{-1}$ TST, or AHI $>1$ event $\cdot \mathrm{h}^{-1}$ TST or AHI $>5$ events $\cdot h^{-1}$ TST), the residual OSAS would still be high (i.e. $7.2-43.5 \%$ ) (table 5). Our study is therefore consistent with previous studies, showing that although T\&A yields significant improvements in respiratory abnormalities in children with OSAS, it is less likely to normalise PSG findings in obese children. Interestingly, the severity of OSAS did not seem affect the response to T\&A, contrary to previous reports [36].

A potential opportunity for intervention that may improve overall T\&A outcomes in obese children with OSAS is the implementation of concurrent dietary modifications aiming at preventing the excessive accelerated weight gain observed in this group [38-40]. There are few studies evaluating the effect of weight loss as a treatment modality for OSAS in obese children. In a study of 61 obese children undergoing an intensive supervised weight-loss programme, despite a higher median relative decrease in BMI Z-score in OSAS compared with obese children without OSAS, 38\% of the children with OSAS still had significant OSAS despite losing weight [7]. However, this study also showed that weight loss is effective in improving or resolving OSAS. In our study, group 2 consisting of children with mild OSAS treated with diet, we observed improvements in respiratory parameters, with half of the children in this group showing resolution of OSAS, albeit with the other half continuing to suffer from OSAS.

Comprehensive analysis of the potential factors associated with the presence, persistence or resolution of OSAS in our cohort led to identification of two significant factors, namely tonsillar hypertrophy and BMI, in addition to age. Notwithstanding, it is apparent that weight accrual in obese patients with OSAS is clearly associated with incidence, persistence or residual OSAS, while weight reductions are associated with improvement in polysomnographic parameters, as evidenced by the significant correlations between changes in BMI and concomitant changes in RDI. In addition, children with residual OSAS show greater weight gain with respect to children without residual OSAS after adenotonsillectomy; therefore, more stringent dietary control in children with OSAS and obesity is necessary. 
Retrognathia and dental malocclusion were included in the analyses as potential factors associated with residual OSAS. Retrognathia was a significant risk factor of residual OSAS in the general lineal model for repeated measures $(\mathrm{p}=0.026)$. However, only $2.6 \%$ of the children included in this study had evidence of retrognathia, which might explain why this risk factor did not achieve statistical significance. Nonetheless, we believe that craniofacial factors need to be evaluated in the context of residual OSAS and, if present, be followed by orthodontic therapy $[13,14]$.

As indicated above, a limitation of this study is the relatively small sample size in each of the subgroups studied and their potential for inducing a beta 2 error. However, we should also remark that our total follow-up sample consisted of 117 obese children, i.e. the largest obese cohort studied thus far in a prospective fashion. We should also consider that the duration of follow-up was somewhat shorter than ideal, whereby recurrence or de novo incidence of OSAS may occur over longer periods of time. Thus, it is possible that the overall frequency of OSAS after treatment may be even greater at 2 or 5 years follow-up. Another possible limitation is the lack of follow-up in 33 children. However as indicated above, no differences in age, sex and BMI Z-score were present between the adherent and lost to follow-up groups. Based on our present findings, we surmise that a greater influence of adenotonsillar hypertrophy appears to be present in younger children in whom obesity operates as an OSAS risk enhancer, while the presence of obesity takes over as the major determinant in older children.

In summary, in addition to the high prevalence of OSAS and the relatively unfavourable OSAS outcomes involved in its treatment and follow-up, current findings place obesity in children as a major public health problem, particularly when considering the potentially serious adverse consequences when obesity and OSAS are concurrently present. These findings also indicate the need to develop effective tools that will enable objective and accurate prediction of the response to treatment of obese children with OSAS [41-45], and the identification of those at risk for developing OSAS with end-organ damage.

\section{Acknowledgements}

The other members of the Spanish Sleep Network are as follows: Estrella Ordax Carbajo (Hospital Universitario de Burgos); Marian Martínez Martínez (Hospital Universitario Valdecilla, Santander); Odile Romero Santo-Tomas (Hospital Val D’Hebron); Fernando Masa-Jimenez (Hospital San Pedro de Alcantara, Caceres); Cristina Martinez Null (Hospital Universitario Araba, Vitoria); Antonia Barcelo-Bennassar (Hospital Son Dureta, Palma de Mallorca, Spain).

\section{References}

1 Gozal D, Capdevila OS, Kheirandish-Gozal L. Metabolic alterations and systemic inflammation in obstructive sleep apnea among nonobese and obese prepubertal children. Am J Respir Crit Care Med 2008; 177: 1142-1149.

2 Bhattacharjee R, Kim J, Kheirandish-Gozal L, et al. Obesity and obstructive sleep apnea syndrome in children: a tale of inflammatory cascades. Pediatr Pulmonol 2011; 46: 313-323.

3 Bhattacharjee R, Kim J, Alotaibi WH, et al. Endothelial dysfunction in children without hypertension: potential contributions of obesity and obstructive sleep apnea. Chest 2012; 141: 682-691.

4 Spruyt K, Gozal D. A mediation model linking body weight, cognition, and sleep-disordered breathing. Am J Respir Crit Care Med 2012; 185: 199-205.

5 Gileles-Hillel A, Alonso-Álvarez ML, Kheirandish-Gozal L, et al. Inflammatory markers and obstructive sleep apnea in obese children: the NANOS study. Mediators Inflamm 2014; 2014: 605280.

6 Verhulst SL, Schrauwen N, Haentjens D, et al. Sleep-disordered breathing in overweight and obese children and adolescents: prevalence, characteristics and the role of fat distribution. Arch Dis Child 2007; 92: 205-208.

7 Verhulst SL, Franckx H, Van Gaal L, et al. The effect of weight loss on sleep-disordered breathing in obese teenagers. Obesity (Silver Spring) 2009; 17: 1178-1183.

8 Van Eyck A, Van Hoorenbeeck K, De Winter BY, et al. Sleep-disordered breathing and pulmonary function in obese children and adolescents. Sleep Med 2014; 15: 929-933.

9 Arens R, Muzumdar H. Childhood obesity and obstructive sleep apnea syndrome. J Appl Physiol 2010; 108: 436-444.

10 Arens R, Sin S, Nandalike K, et al. Upper airway structure and body fat composition in obese children with obstructive sleep apnea syndrome. Am J Respir Crit Care Med 2011; 183: 782-787.

11 Nandalike K, Shifteh K, Sin S, et al. Adenotonsillectomy in obese children with obstructive sleep apnea syndrome: magnetic resonance imaging findings and considerations. Sleep 2013; 36: 841-847.

12 Alonso-Álvarez ML, Cordero-Guevara JA, Terán-Santos J, et al. Obstructive sleep apnea in obese community-dwelling children: the NANOS study. Sleep 2014; 37: 943-949.

13 Marcus CL, Brooks LJ, Draper KA, et al. Diagnosis and management of childhood obstructive sleep apnea syndrome. Pediatrics 2012; 130: e714-e755.

14 Luz Alonso-Álvarez M, Canet T, Cubell-Alarco M, et al. [Consensus document on sleep apnea-hypopnea syndrome in children (full version). Sociedad Española de Sueño. El Área de Sueño de la Sociedad Española de Neumología y Cirugía Torácica (SEPAR).] Arch Bronconeumol 2011; 47: Suppl. 5, 2-18.

15 Mitchell RB, Kelly J. Adenotonsillectomy for obstructive sleep apnea in obese children. Otolaryngol Head Neck Surg 2004; 131: 104-108.

16 Guilleminault $\mathrm{C}, \mathrm{Li} \mathrm{K}$, Quo S, et al. A prospective study on the surgical outcomes of children with sleep-disordered breathing. Sleep 2004; 27: 95-100.

17 Mitchell RB, Kelly J. Outcome of adenotonsillectomy for obstructive sleep apnea in children under 3 years. Otolaryngol Head Neck Surg 2005; 132: 681-684. 
18 Guilleminault C, Kasey KL, Khramtsov A, et al. Sleep disordered breathing: surgical outcomes in prepubertal children. Laryngoscope 2004; 114: 132-137.

19 Lipton AJ, Gozal D. Treatment of obstructive sleep apnea in children: do we really know how? Sleep Med Rev 2003; 7: 61-80.

20 Alonso-Alvarez ML, Navazo-Egüia AI, Cordero-Guevara JA, et al. Respiratory polygraphy for follow-up of obstructive sleep apnea in children. Sleep Med 2012; 13: 611-615.

21 Friedman M, Wilson M, Lin HC, et al. Updated systematic review of tonsillectomy and adenoidectomy for treatment of pediatric obstructive sleep apnea/hypopnea syndrome. Otolaryngol Head Neck Surg 2009; 140: $800-808$.

22 Costa DJ, Mitchell R. Adenotonsillectomy for obstructive sleep apnea in obese children: a meta-analysis. Otolaryngol Head Neck Surg 2009; 140: 455-460.

23 Serra Majem L, Ribas Barba L, Aranceta B, et al. Obesidad infantil y juvenil en España. Resultados del Estudio enKid (1998-2000). Med Clin Barc 2003; 121: 725-732.

24 Pérez-Farinós N, López-Sobaler AM, Dal Re MÁ, et al. The ALADINO study: a national study of prevalence of overweight and obesity in Spanish children in 2011. Biomed Res Int 2013; 2013: 163687.

25 Sobradillo B, Aguirre A, Aresti U, et al. Curvas y tablas de crecimiento (estudio longitudinal y trasversal). In: Fundación F. Orbegozo, ed. Patrones de crecimiento y desarrollo en España. Atlas de gráficas y tablas. Madrid, Ergon, 2004, pp. 1-31.

26 Cole T, Bellizzi M, Flegal K, et al. Establishing a standard definition for child overweight and obesity worldwide: international survey. BMJ 2000; 320: 1240-1243.

27 Tomás Vila M, Miralles Torres A, Beseler Soto B. Spanish version of the Pediatric Sleep Questionnaire (PSQ). A useful instrument in investigation of sleep disturbances in childhood. Reliability analysis. Ann Pediatr 2007; 66: $121-128$

28 Iber C, Ancoli-Israel S, Chesson A, et al. The AASM manual for scoring of sleep and associated events: rules, terminology and technical specifications. 1st edn. Westchester, American Academy of Sleep Medicine, 2007.

29 Kushida CA, Chediak A, Berry RB, et al. Clinical guidelines for the manual titration of positive airway pressure in patients with obstructive sleep apnea. J Clin Sleep Med 2008; 4: 157-171.

30 Tauman R, Gulliver TE, Krishna J, et al. Persistence of obstructive sleep apnea syndrome in children after adenotonsillectomy. J Pediatr 2006; 149: 803-808.

31 Mitchell RB, Kelly J. Outcome of adenotonsillectomy for obstructive sleep apnea in obese and normal-weight children. Otolaryngol Head Neck Surg 2007; 137: 43-48.

32 Verhulst SL, Van Gaal L, De Backer W, et al. The prevalence, anatomical correlates and treatment of sleep-disordered breathing in obese children and adolescents. Sleep Med Rev 2008; 12: 339-346.

33 Bhattacharjee R, Kheirandish-Gozal L, Spruyt K, et al. Adenotonsillectomy outcomes in treatment of obstructive sleep apnea in children: a multicenter retrospective study. Am J Respir Crit Care Med 2010; 182: 676-683.

34 Marcus CL, Moore RH, Rosen CL, et al. A randomized trial of adenotonsillectomy for childhood sleep apnea. N Engl J Med 2013; 368: 2366-2376.

35 O'Brien LM, Sitha S, Baur LA, et al. Obesity increases the risk for persisting obstructive sleep apnea after treatment in children. Int J Pediatr Otorhinolaryngol 2006; 70: 1555-1560.

36 Tagaya M, Nakata S, Yasuma F, et al. Children with severe or moderate obstructive sleep apnoea syndrome show a high incidence of persistence after adenotonsillectomy. Acta Otolaryngol 2012; 132: 1208-1214.

37 Apostolidou MT, Alexopoulos EI, Chaidas K, et al. Obesity and persisting sleep apnea after adenotonsillectomy in Greek children. Chest 2008; 134: 1149-1155.

38 Gkouskou KK, Vlastos IM, Hajiioannou I, et al. Dietary habits of preschool aged children with tonsillar hypertrophy, pre- and post-operatively. Eur Rev Med Pharmacol Sci 2010; 14: 1025-1030.

39 Amin R, Anthony L, Somers V, et al. Growth velocity predicts recurrence of sleep-disordered breathing 1 year after adenotonsillectomy. Am J Respir Crit Care Med 2008; 177: 654-659.

40 Katz ES, Moore RH, Rosen CL, et al. Growth after adenotonsillectomy for obstructive sleep apnea: an RCT. Pediatrics 2014; 134: 282-289.

41 Gozal D. Serum, urine, and breath-related biomarkers in the diagnosis of obstructive sleep apnea in children: is it for real? Curr Opin Pulm Med 2012; 18: 561-567.

42 De Luca Canto G, Pachêco-Pereira C, Aydinoz S, et al. Diagnostic capability of biological markers in assessment of obstructive sleep apnea: a systematic review and meta-analysis. J Clin Sleep Med 2014; 11: 27-36.

43 Kheirandish-Gozal L, Gozal D. Genotype-phenotype interactions in pediatric obstructive sleep apnea. Respir Physiol Neurobiol 2013; 189: 338-343.

44 Khalyfa A, Gozal D. Exosomal miRNAs as potential biomarkers of cardiovascular risk in children. J Transl Med 2014; $12: 162$.

45 Kheirandish-Gozal L, Gileles-Hillel A, Alonso-Álvarez ML, et al. Effects of adenotonsillectomy on plasma inflammatory biomarkers in obese children with obstructive sleep apnea: a community-based study. Int J Obes (Lond) 2015; 39: 1094-1100 